\title{
Stochastic finite-fault simulation of the 2017 Jiuzhaigou earthquake in China
}

\author{
JiZe Sun ${ }^{1,2}$, YanXiang $\mathrm{Yu}^{1 *}$ and YiQiong $\mathrm{Li}^{1}$
}

\begin{abstract}
In this study, the strong ground motion of the Jiuzhaigou Ms7.0 earthquake, which occurred in northern Sichuan, China, was simulated based on the stochastic finite-fault method. The earthquake event was recorded by 66 strong ground-motion stations operated by the China Strong Motion Networks Center. We simulated 11 records selected within $200 \mathrm{~km}$ source-to-site distance. According to previous studies and empirical relationships, we estimated the region-specific input parameters. The zero-distance kappa filter obtained had a value of $0.0206 \mathrm{~s}$. Two different source models were applied in this study: the random slip model and specified slip model. Using the stochastic finite-fault method, we simulated the PGA, Fourier spectrum and response spectrum at all stations. The stochastic simulated result based on the specified slip distribution models had no significant bias at most stations. Using a model with a random slip distribution, the simulated response spectra also matched the observed result, which indicated that the stochastic finite-fault method is not very sensitive to the input slip distributions and fault dimensions. We divided the study area into 1116 sites to simulate the spatial distribution of PGA based on the two models. The simulated maximum intensity of the epicentral area reached level IX, which was similar to the observed maximum intensity and indicated that the simulated result could be used in prediction of an imminent earthquake disaster. For future earthquake prediction, seismic hazards could even be estimated quickly without obtaining detailed information about the fault plane.
\end{abstract}

Keywords: Stochastic finite-fault model, Strong ground-motion simulation, Site amplification, Jiuzhaigou earthquake

\section{Introduction}

On August 8, 2017 at 13:19 (local time), an earthquake with magnitude Ms7.0 occurred in Jiuzhaigou County of Sichuan Province at the eastern margin of the Tibetan Plateau. According to the China Earthquake Networks Center (CENC 2017), the epicenter was located at $33.20^{\circ} \mathrm{N}, 103.82^{\circ} \mathrm{E}$ and had a focal depth of $20 \mathrm{~km}$. This powerful earthquake significantly impacted society and the natural environment. It was reported that the earthquake caused 25 deaths and injured more than 500 people. The seismic intensity from the field survey in the magistoseismic area reached IX, and the affected area with seismic intensity greater than VI was approximately $18,295 \mathrm{~km}^{2}$.

\footnotetext{
*Correspondence: yuyx@cea-igp.ac.cn

${ }^{1}$ Institute of Geophysics, China Earthquake Administration, Beijing 100081, China

Full list of author information is available at the end of the article
}

The Jiuzhaigou earthquake was located in the region between the eastern Kunlun fault system and the Longmen Shan fault system. This region is tectonically complex with high seismicity, which is related to the extrusion of the Indian Plate to the Eurasian Plate. The seismogenic fault for the Jiuzhaigou earthquake was associated with a blind fault not shown on the Chinese active fault map (Han et al. 2018). The epicenter was close to the Minjiang, Tazang and Huya faults (Han et al. 2018). Based on the CAP waveform inversion method, Yi et al. (2017) gave the focal mechanism solution to this earthquake. The strikes, dips and rakes of the two nodal planes of the focal mechanism are $156^{\circ} / 79^{\circ} /-9^{\circ}$ and $248^{\circ} / 81^{\circ} /-169^{\circ}$, which are similar to the results from the global centroid moment tensor and USGS solutions. According to the focal mechanism solutions and the spatial distribution of aftershocks, the seismogenic fault for the Jiuzhaigou earthquake was a left-lateral strike-slip fault and is 
considered to have ruptured a branch of the eastern Kunlun fault system.

The stochastic finite-fault simulation method has been widely recognized as one of the most important tools for generation of synthetic ground-motion records. This method has previously been used to simulate strong motions from several large earthquakes including the 1999 Mw7.6 Chi-Chi earthquake (Roumelioti and Beresnev 2003), $2008 M w 8.0$ Wenchuan earthquake (Ghasemi et al. 2010) and 2011 Mw9.0 Tohoku earthquake (Ghofrani et al. 2013). Compared with deterministic and hybrid ground-motion simulation methods, the advantages of the stochastic method are its independence from small earthquake selection and good performance at high frequencies (Motazedian and Atkinson 2005).

In this study, we applied the stochastic finite-fault method proposed by Motazedian and Atkinson (2005) to simulate and analyze accelerograms and response spectra of the Jiuzhaigou earthquake. The region-specific seismic parameters including anelastic attenuation, local site effects and path effects were estimated from previous studies and empirical relationships. Once input parameters were calibrated, ground-motion characteristics such as peak ground acceleration (PGA), Fourier spectra and response spectra were estimated and compared with the observations at all 11 stations. Then, we used the model parameters to simulate the ground scenario in the study area.

\section{Ground-motion data}

The earthquake event was recorded by 66 strong groundmotion stations operated by the China Strong Motion Networks Center (CSMNC). All of the accelerograms were recorded by digital instruments (MR2002/SLJ-100, ETNA/ES-T, and ETNA/SLJ-100). The sample rate was
$200 \mathrm{~Hz}$, and the preceding $20 \mathrm{~s}$ was prestored as the preevent part.

In this paper, we selected those records with source-tosite distances within $200 \mathrm{~km}$ to simulate. The quality of each record was evaluated based on the signal-to-noise ratio technique $(\mathrm{SNR} \geq 3)$. All ground-motion records were baseline-corrected via removal of the mean and the linear trend in recorded acceleration and then bandpass-filtered in the frequency range of $0.02-20 \mathrm{~Hz}$ with a fourth-order Butterworth filter. This frequency band included the main destructive and representative characteristics of the ground motion. The entire database consists of 11 sets of ground-motion time histories. Table 1 lists the stations used in this study along with geographical location, instrument type, site condition, $\mathrm{V}_{\mathrm{S} 30}$ and epicentral distances. The site class was based on the surface geology reported by the CSMNC and $V_{\mathrm{s} 30}$ data derived from the work of Yan et al. (2016). Figure 1 shows the locations of the recording stations, as well as the projection of the fault plane and the epicenter of the earthquake. The maximum amplitudes for this earthquake were recorded at station JZB, where peak ground acceleration (PGA) was $185 \mathrm{~cm} / \mathrm{s}^{2}$ for the north-south components.

\section{Methodology}

In stochastic finite-fault modeling, a large fault is divided into $N$ subfaults, and each subfault is considered as a point source. Each subfault is simulated using a stochastic point source method. The Fourier acceleration amplitude spectrum is a result of contributions from the earthquake source, path attenuation and site effect, and the radiation from a specific site can be defined by

$$
A(\omega)=C \cdot \operatorname{Source}\left(M_{0}, f\right) \cdot \operatorname{Path}(R, f) \cdot \operatorname{Site}(f),
$$

Table 1 Information on the strong-motion stations used in this study

\begin{tabular}{|c|c|c|c|c|c|c|c|}
\hline \multirow[t]{2}{*}{ Station code } & \multirow[t]{2}{*}{ Lat $\left({ }^{\circ} \mathrm{N}\right)$} & \multirow[t]{2}{*}{ Lon $\left({ }^{\circ} \mathrm{E}\right)$} & \multicolumn{2}{|c|}{$P G A\left(\mathrm{~cm} / \mathrm{s}^{2}\right)$} & \multirow[t]{2}{*}{$V s_{30}(m / s)$} & \multirow[t]{2}{*}{ Site class } & \multirow{2}{*}{$\begin{array}{l}\text { Epicentra } \\
\text { distance } \\
(\mathrm{km})\end{array}$} \\
\hline & & & EW & NS & & & \\
\hline$J Z B$ & 33.3 & 104.1 & 129.5 & 185.0 & 323 & Soil & 30.6 \\
\hline$J Z Y$ & 33.2 & 104.3 & 45.8 & 66.7 & 312 & Soil & 40.3 \\
\hline$J Z W$ & 33.0 & 104.2 & 73.8 & 91.7 & 422 & Soil & 41.0 \\
\hline SHW & 33.7 & 104.5 & 18.6 & 20.5 & - & Soil & 83.4 \\
\hline PWM & 32.6 & 104.5 & 18.6 & 20.9 & 357 & Soil & 91.8 \\
\hline $\mathrm{DIB}$ & 34.1 & 103.2 & 13.6 & 8.1 & - & Soil & 115.4 \\
\hline MXD & 32.0 & 103.7 & 12.2 & 23.3 & 267 & Soil & 129.7 \\
\hline MXT & 31.7 & 103.9 & 23.5 & 21.6 & - & Soil & 138.0 \\
\hline HSS & 31.9 & 103.4 & 8.6 & 6.4 & - & Soil & 149.8 \\
\hline MXN & 31.6 & 103.7 & 6.3 & 6.6 & 391 & Soil & 180.3 \\
\hline LXT & 31.6 & 103.5 & 3.4 & 3.4 & 316 & Soil & 185.6 \\
\hline
\end{tabular}




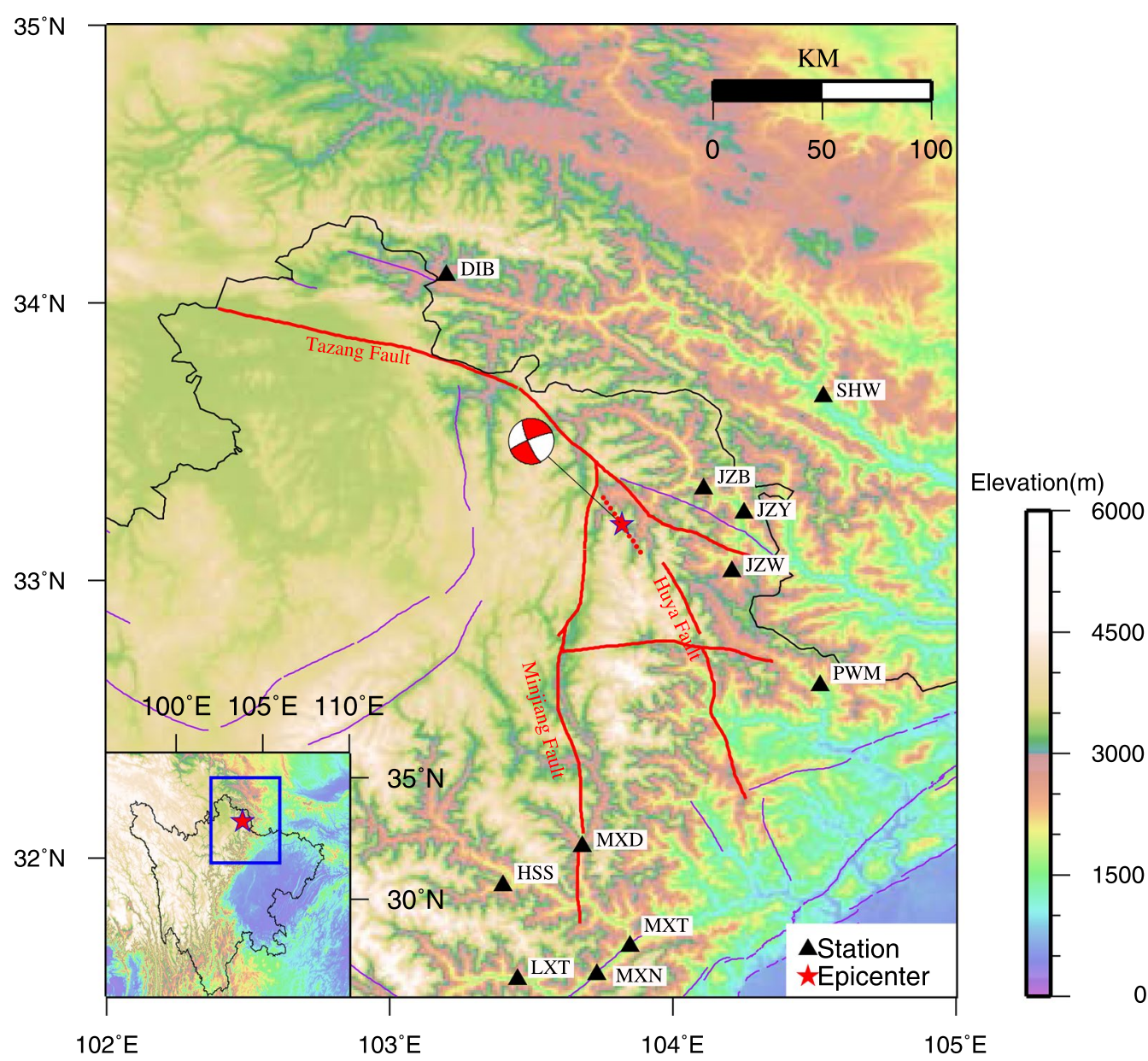

Fig. 1 Map showing the tectonic setting of the Jiuzhaigou area. Red stars indicated the epicenter of the Ms7.0 Jiuzhaigou earthquake. The Minjiang, Tazang and Huya active faults are indicated by red lines. Beach ball diagrams are from CENC. Black triangles denote the locations of ground-motion stations. The details of ground-motion stations are listed in Table 1. The inset shows the location of the current working area

where $C$ is the scaling factor, $M_{0}$ is the moment and $R$ is the shortest distance from the source to the site. The $\operatorname{Source}\left(M_{0}, f\right)$ is the displacement source spectrum given by Brune's omega-squared model and is presented by

$$
\operatorname{Source}\left(M_{0}, \omega\right)=\frac{M_{0}}{1+\left(f / f_{\mathrm{c}}\right)^{2}}
$$

where $f_{\mathrm{c}}$ is the source corner frequency represented by

$$
f_{\mathrm{c}}=4.9 \times 10^{6} \beta\left(\Delta \sigma / M_{0}\right)^{1 / 3},
$$

where $\Delta \sigma$ is the stress drop parameter in bars, and $\beta$ is the shear-wave velocity in $\mathrm{km} / \mathrm{s}$.

The path effects Path $(R, f)$ are modeled by multiplication of geometrical spreading and anelastic attenuation functions in the frequency domain (Boore 2003) as

$$
\operatorname{Path}(R, f)=G(R) \cdot \operatorname{An}(f, R),
$$

where $G(R)$ is the distance-dependent geometrical spreading function, $\operatorname{An}(f, R)=\exp [-\pi f R / Q(f) \beta]$ is the anelastic whole path attenuation function, where $Q(f)$ is the frequency-dependent quality factor and $\beta$ is the shear-wave velocity of the crust. The path effects depend on the source location due to different paths between source and site and control the attenuation characteristics of simulated ground motion.

The site effects include the upper crust amplification factor $\operatorname{Am}(f)$ and the upper crust attenuation factor $V(f)$ :

$$
\operatorname{Site}(R, f)=\operatorname{Am}(f) \cdot V(f)
$$

The amplification factor mainly results from the seismic impedance effect through the velocity gradient in the surface layers. There are several methods to estimate the site amplification, such as the standard spectral ratio method and the horizontal-to-vertical ratio method. The upper crust attenuation factor is a high-frequency 
truncation filter, commonly described as a high-cut filter, which is controlled by the kappa parameter. The decay parameter kappa represents the effect of intrinsic attenuation upon the wave field as it propagates through below the site.

The rupture starts from the hypocenter and triggers the nearby subfaults when the rupture spreads to their centers. Then, the spectra of subfaults are Fourier transformed to the time domain. The total ground motion at the site is obtained by summing up the contribution of each subfault with a proper delay time:

$$
a(t)=\sum_{i=1}^{n l} \sum_{j=1}^{n w} a_{i j}\left(t+\Delta t_{i j}\right),
$$

where $n l$ and $n w$ are the numbers of subfaults along the strike and dip of the main fault, respectively, and $\Delta t_{i j}$ is the relative delay time from the $i j$ th subfault to the site.

\section{Modeling parameters}

The stochastic finite-fault simulation method needs to take into account the effects of source, path and siteeffect parameters within the region of interest in order to generate the best results. Several parameters need to be defined as they control the physical aspects of ground motion. The parameters used in the present study were estimated based on published information or constrained from the available data. The input parameters are summarized in Table 2.
In the present study, we used the source parameters given by CENC where the epicenter of the earthquake obtained was $33.20^{\circ} \mathrm{N}, 103.82^{\circ} \mathrm{E}$ and the focal depth was $20 \mathrm{~km}$. The stress drop parameter was the most important parameter controlling the high-frequency spectral amplitudes and high-frequency energy content. According to the research of Wang et al. (2017), the stress drop for this earthquake was 38.5 bars. The fault dimension and slip distribution affected the high-frequency seismic radiation (Causse et al. 2010), which controlled the seismic moment of each subfault. In this study, we used two different fault models to investigate the effects of different source models on the variations in the groundmotion levels.

\section{Slip model 1}

According to the joint inversions of InSAR data and teleseismic waveforms by Zhang et al. (2017), the dimension of the fault rupture plane was divided into 21 subfaults along the strike and 20 subfaults along the down-dip direction. The total length and width were $32 \mathrm{~km}$ and $30 \mathrm{~km}$, respectively. Figure 2 depicts the slip distributions and fault dimension of model 1.

\section{Slip model 2}

For model 2, we used the random slip model and the central starting point in order to simulate future events for which the corresponding slip distribution will be unknown. The fault plane dimension was estimated by the empirical relationship of Leonard (2010). The fault plane was divided into $23 \times 15$ subfaults with dimensions of $1 \mathrm{~km} \times 1 \mathrm{~km}$.

Table 2 Input parameters for the stochastic finite-fault model of the Jiuzhaigou earthquake

\begin{tabular}{|c|c|c|}
\hline Parameters & Model & Reference \\
\hline Moment magnitude (Mw) & 6.5 & CENC \\
\hline Hypocenter location & $103.82^{\circ} \mathrm{E}, 33.20^{\circ} \mathrm{N}$ & CENC \\
\hline Strike and dip angle & $156^{\circ}, 79^{\circ}$ & Yi et al. (2017) \\
\hline fault length and width (km) & $\begin{array}{l}\text { Model } 1: 32 \times 30(1.52 \times 2) \\
\text { Model } 2: 23 \times 15(1 \times 1)\end{array}$ & $\begin{array}{l}\text { Zhang et al. (2017) } \\
\text { Leonard (2010) }\end{array}$ \\
\hline Slip distribution & $\begin{array}{l}\text { Model 1: estimated by Zhang et al. (2017) } \\
\text { Model 2: random distribution }\end{array}$ & Zhang et al. (2017) \\
\hline Stress drop (bars) & 38.5 & This study \\
\hline Shear-wave velocity (km/s) & 3.6 & Ghasemi et al. (2010) \\
\hline Density $\left(\mathrm{g} / \mathrm{cm}^{3}\right)$ & 2.7 & Ghasemi et al. (2010) \\
\hline Rupture velocity & $0.8 \times($ Shear-wave velocity) & Ghasemi et al. (2010) \\
\hline Pulsing area percentage & $50 \%$ & Ghasemi et al. (2010) \\
\hline Geometric spreading & $1 / R$ for $R \leq 75 \mathrm{~km}, 1 / R^{0.5}$ for $75 \mathrm{~km} \leq R$ & Ghasemi et al. (2010) \\
\hline Distance-dependent duration & $\begin{array}{l}0 \text { for } R \leq 10 \mathrm{~km}, 0.16 R \text { for } 10<R \leq 70 \mathrm{~km},-0.03 R \text { for } 70<R \leq 130 \mathrm{~km} \text {, } \\
\quad-0.04 R \text { for } 130 \mathrm{~km}<R\end{array}$ & Atkinson and Boore (1995) \\
\hline Quality factor & $84.9 f^{0.71}$ & Wang et al. (2017) \\
\hline Site amplification & Quarter-wavelength approximation of amplification & Yu and Li (2012) \\
\hline Kappa (s) & 0.0206 & This study \\
\hline
\end{tabular}




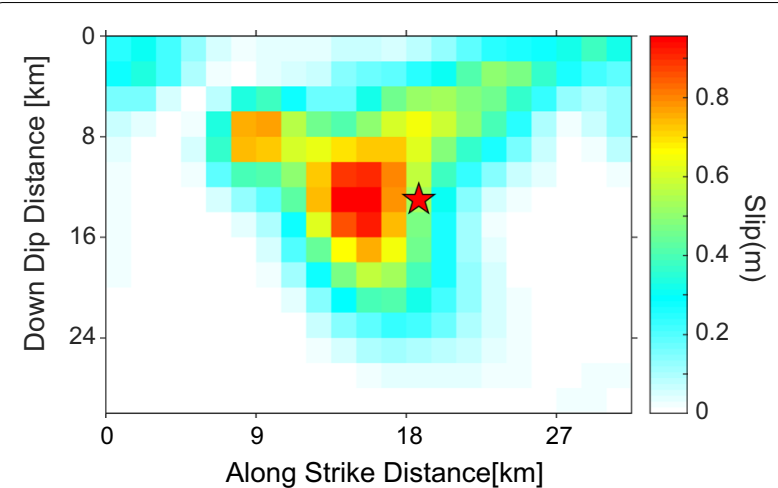

Fig. 2 Slip distribution based on joint inversions of InSAR data and teleseismic waveforms (Zhang et al. 2017). The hypocenter location is denoted by a red star. The slip amplitudes are shown in colors

Path effects were defined as a combination of geometrical spreading, anelastic attenuation and ground-motion duration effects. For the anelastic attenuation, the frequency-dependent relation quality factor $Q=84.9 f^{0.71}$ obtained from Wang et al. (2017) for the northwest Sichuan region was used in the present study. To account for the geometrical spreading, we used a bilinear model defined in Ghasemi et al. (2010) to express the geometric spreading function. The bilinear model was simply assumed to be $1 / R$ for distances less than $75 \mathrm{~km}$ and $1 / R^{0.5}$ for distances beyond $75 \mathrm{~km}$. The ground-motion duration at hypocentral distance could be represented by a distance-dependent duration model obtained by Atkinson and Boore (1995).
The site effects included site amplification and nearsurface attenuation. The overall site amplification functions were derived from the work of $\mathrm{Yu}$ and $\mathrm{Li}$ (2012), which were generated by using the quarter-wavelength method (Joyner et al. 1981). The high-frequency decay parameter $(\kappa)$ represented the high-frequency attenuation of seismic waves due to local site conditions. Several studies have explored the relationships between geotechnical site properties and $\kappa . \kappa$ can be related to the frequency-independent quality factor (Motazedian 2006; Ugurhan and Askan 2010). Ktenidou et al. (2015) suggested that hard-rock sites have a lower bound for $\kappa$. Fu et al. (2016) reported that $\kappa$ values for horizontal and vertical components are closely related to elevation and velocity images at $0-10 \mathrm{~km}$ depth. In this study, the spectral decay method proposed by (Anderson and Hough 1984) was applied

$$
A(f)=A_{0} \exp (-\pi \kappa(R) f), \quad f_{\max } \geq f \geq f_{e},
$$

in which $f_{e}$ represents the starting frequency of the linear trend, $f_{\max }$ denotes the ending frequency (Douglas et al. 2010) and $R$ is the epicentral distance. We estimated $\kappa$ in the Jiuzhaigou region using data from moderate-tolarge earthquakes recorded by the CSMNC during the 2008 Wenchuan and 2017 Jiuzhaigou earthquakes. The distribution of the $\kappa$ values with the epicentral distance of the recording seismic stations is shown in Fig. 3. The best fit line to the $\kappa$ factor for the average horizontal components versus epicentral distance was obtained as $0.00005 R+0.0206$.

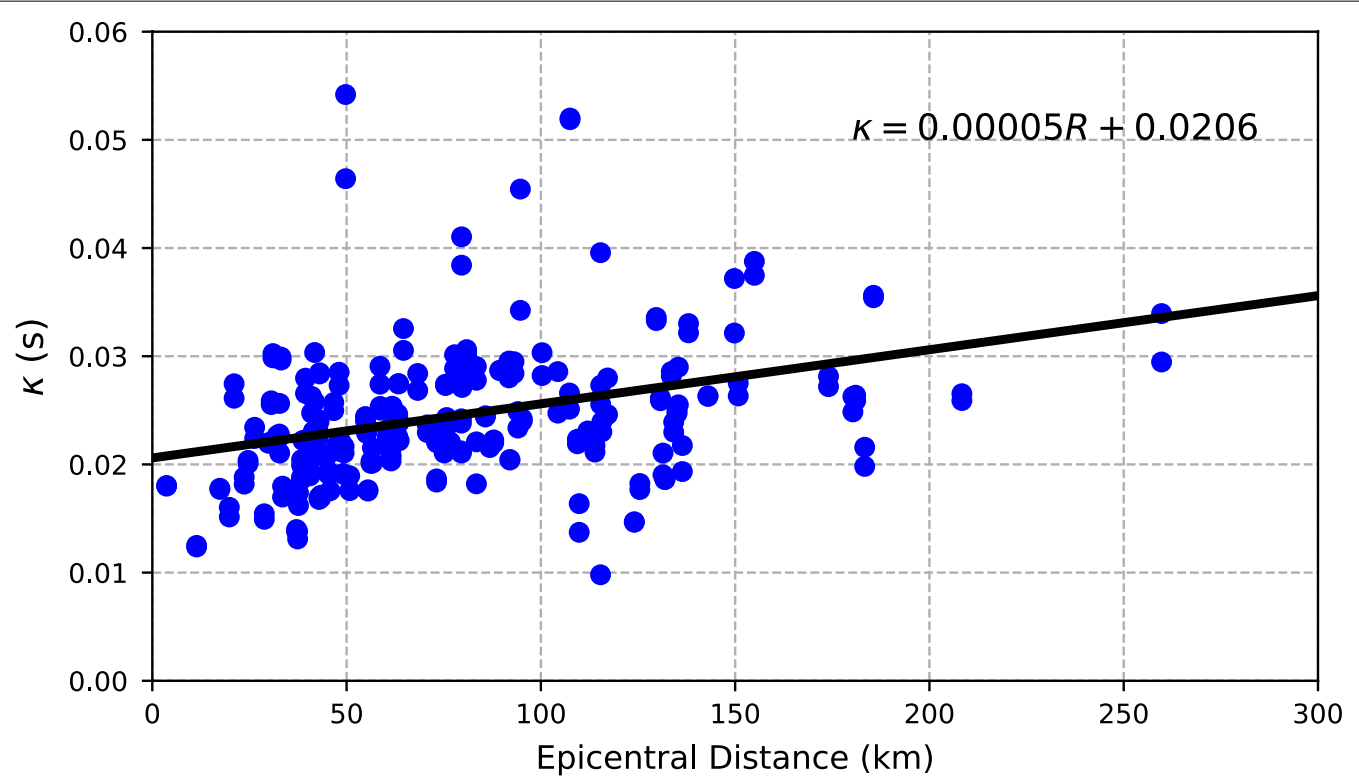

Fig. 3 Distance dependence of horizontal kappa $(k)$. The regression line uses standard linear regression 
The other source parameters, namely material density, shear-wave velocity and pulsing percentage, were assigned with commonly used values according to a previous study on Wenchuan earthquake simulation (Ghasemi et al. 2010).

\section{Results and discussion}

\section{Comparison of the different models}

Using the model parameters listed in Table 2, we simulated the ground-motion record and compared it with the observed acceleration time series and Fourier amplitude spectra (FAS) as well as the $5 \%$-damped pseudo-acceleration response spectra (PSA) in the EW and NS directions for all selected stations. For the FAS and 5\%-damped PSA, we used the horizontal-component geometric mean of the observed ground motion to compare with the simulated record. For simulated acceleration time series, we selected the one with peak value closest to the average of ten trials.

In Figs. 4, 5 and 6, we compare the simulated accelerograms for different source models with the observed acceleration at three representative stations with different azimuth coverage. As can be seen, the time series are reasonably similar between the observed and simulated records for both models, and the simulated FAS and PSA match very well with the observed values. Through the comparison of the 5\%-damped PSA for the simulated and observed ground motions (Fig. 7), we find that the stations have good spectral fitting. At near-fault stations such as JZB, JZW, JZY, SHW and PWM, simulated spectra from model 1 and model 2 match sufficiently with observed spectra. At far-fault stations such as MXT, MXD and MXN, the simulated spectra from the two models are underestimated at high frequencies $(>1 \mathrm{~Hz})$. We observe that the PGA values generally match well with the observations at most of the stations (Fig. 8). In the stochastic simulation method, we simplified the model of the source, path and site effects for such a complex event. This simplification may have caused the discrepancies between the simulated and observed results. If more information regarding site amplification and path effects was
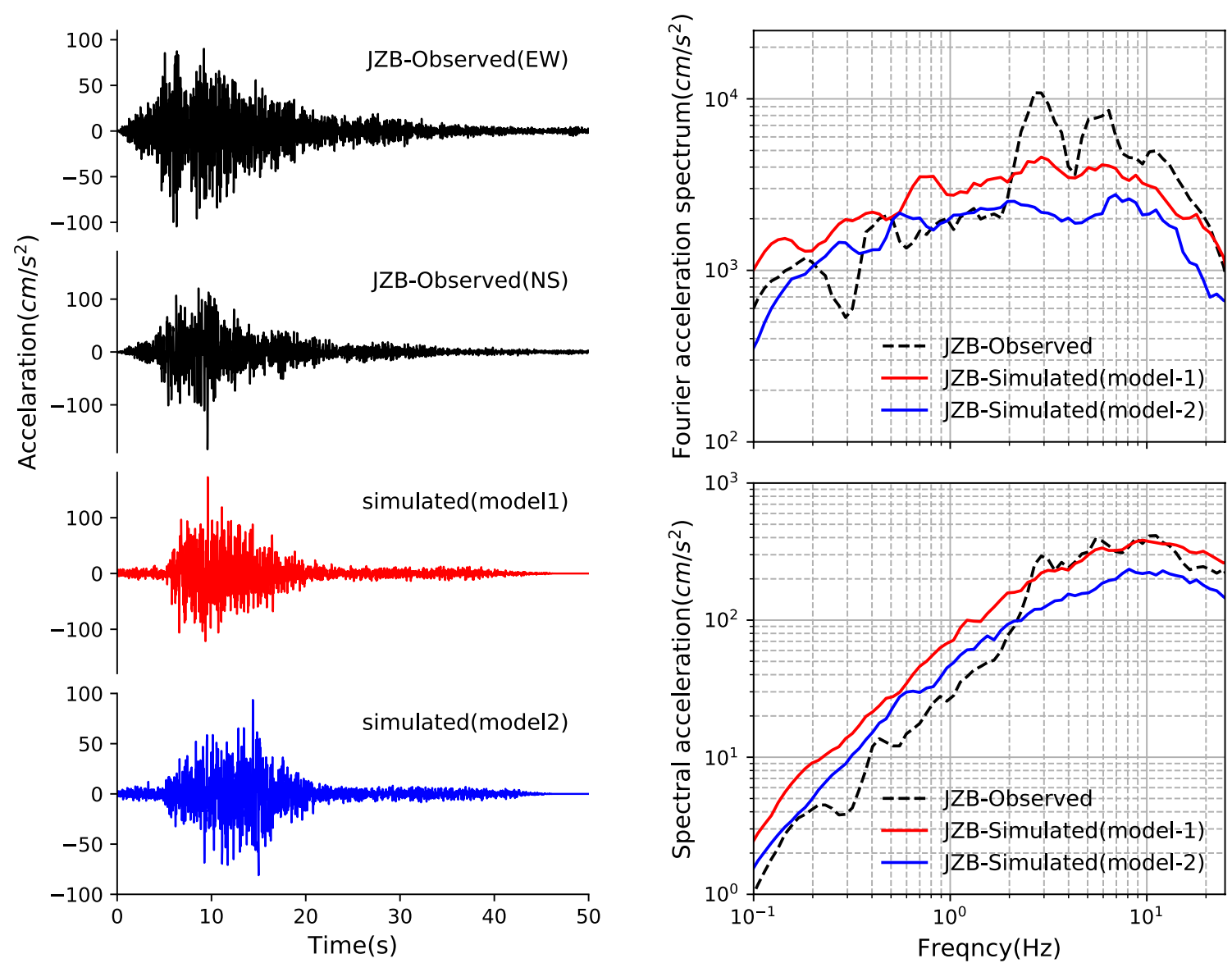

Fig. 4 Comparison of simulated and observed horizontal strong motions at JZB station. The observed (dashed lines) and simulated (solid lines) Fourier amplitude spectra and the response spectra of acceleration are also shown 

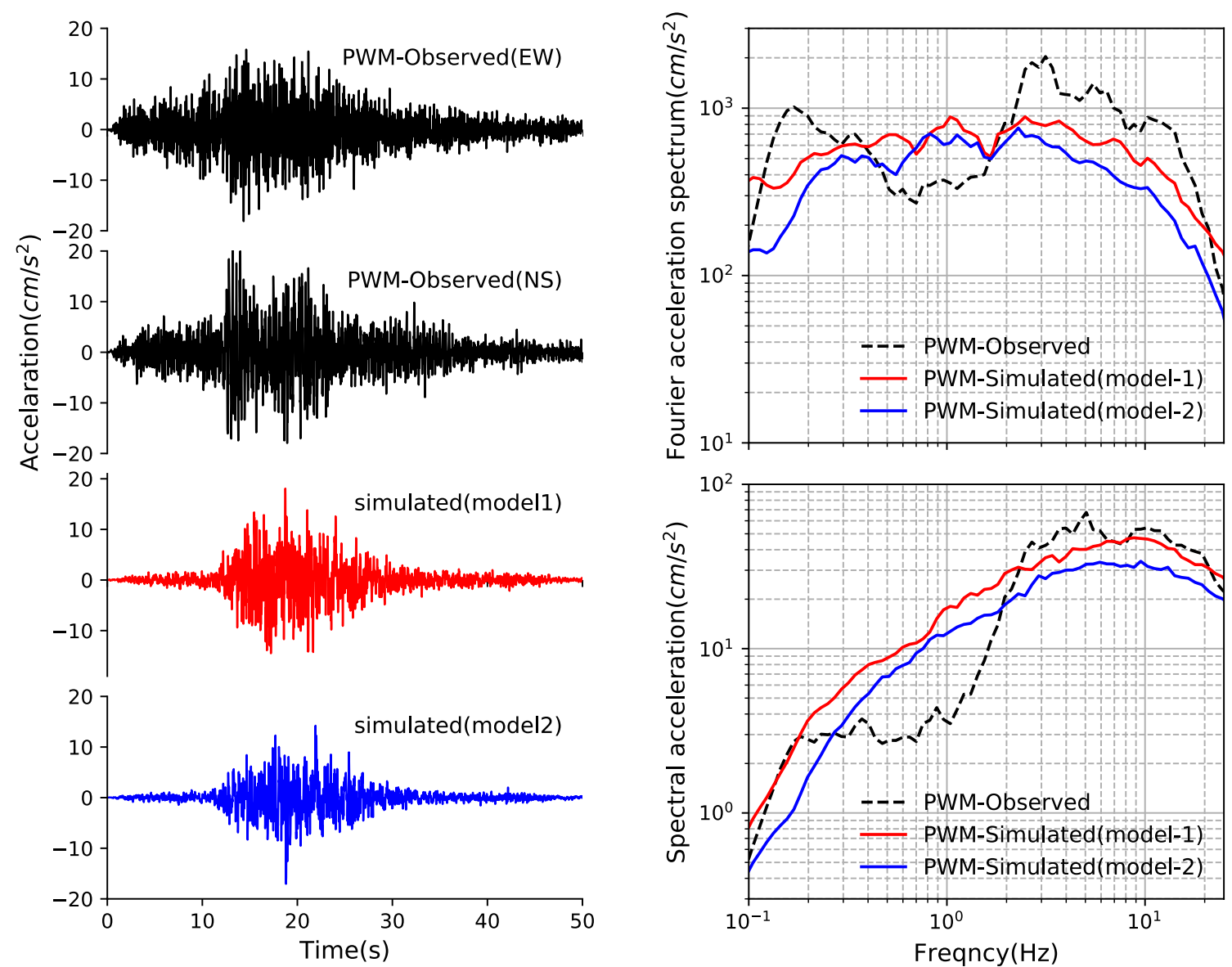

Fig. 5 Comparison of simulated and observed horizontal strong motions at PWM station. The observed (dashed lines) and simulated (solid lines) Fourier amplitude spectra and the response spectra of acceleration are also shown

included, the simulated results would be further impr oved.

We also calculated the overall PSA spectral residuals for all records to compare the goodness of fit from different models. The residuals at each station were calculated as the logarithm (base 10) of the ratios of simulated PSA to observed PSA. The distributions of residuals versus fault distance at nine representative frequencies are shown in Fig. 9. The distributions of residuals shown in the plots for most of the frequencies are closely distributed around zero. For the low-frequency range between 0.1 and $1 \mathrm{~Hz}$, both model 1 and model 2 overestimate the observed records. The discrepancy at the lower frequencies might be attributed to the inherent limitations of stochastic methods that simplify the complexity of the rupture and propagation processes. In the frequency range between 3 and $20 \mathrm{~Hz}$, the residuals of model 1 are lower than those of model 2 in most of the stations. These differences verify that the slip distribution and fault dimension affected the seismic radiation in the whole frequency band. Although the simulated results from the two models have some differences, all of the model residuals are within the error range. This result means that the quality of the simulated results has little affect by the slip distribution.

\section{Spatial distribution of ground-motion intensity}

Figure 10 displays the distribution patterns of simulated PGAs from the two slip models. We use two model parameters for simulated ground motions in the study area. The study area is divided into approximately 1116 grids with a size of $0.1^{\circ}$ covering an area of $31.5-35^{\circ} \mathrm{N}$, 102.0-105 ${ }^{\circ} \mathrm{E}$.

From the PGA distributions of the two models, we find that the main influence area of PGA obtained from model 1 is obviously greater than that from model 2 . This result is matched to the area of the fault distribution. The distribution ranges of PGA values are approximately matched with the field observations, which are extended along the northwest direction with the highest amplitudes localized 

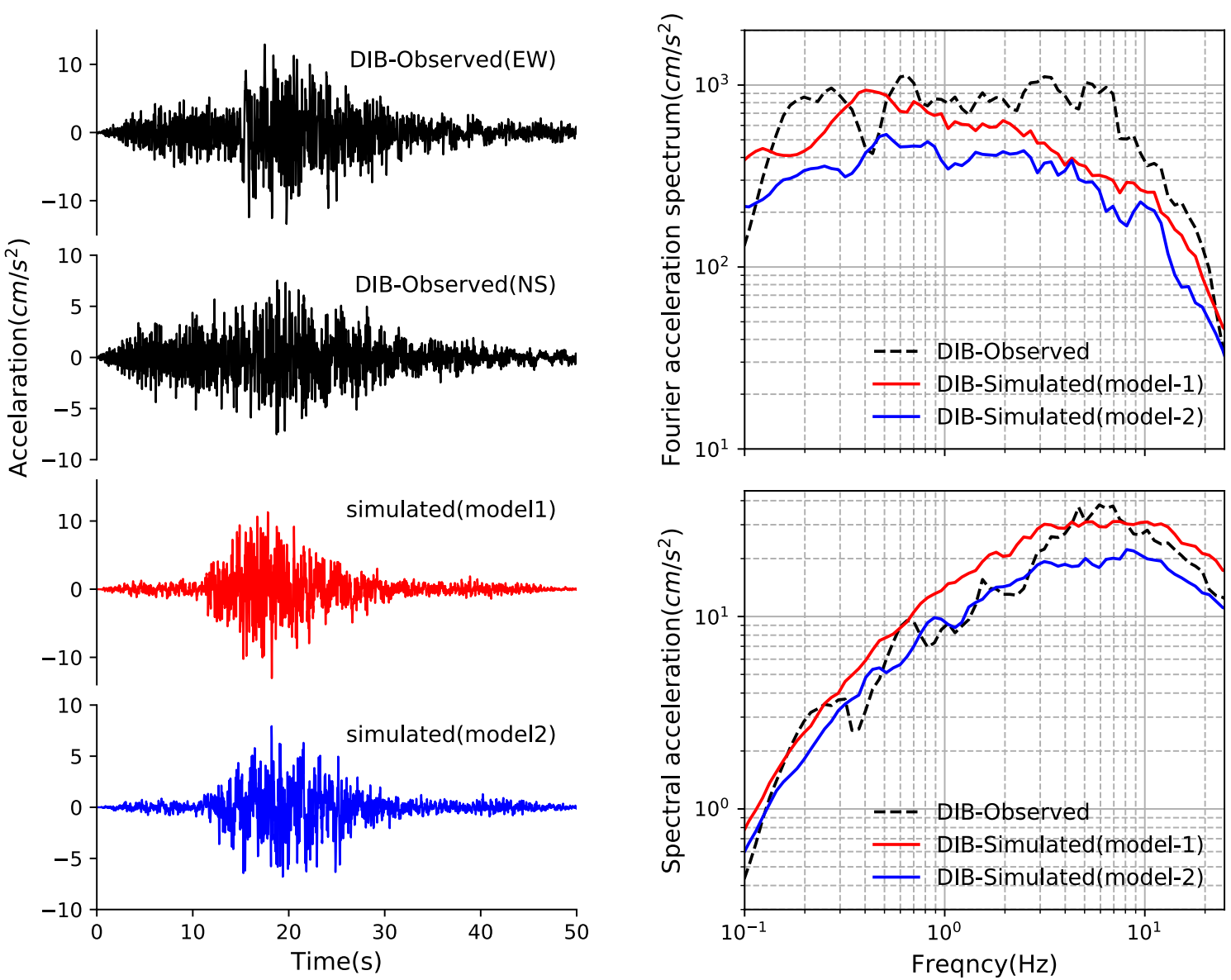

Fig. 6 Comparison of simulated and observed horizontal strong motions at DIB station. The observed (dashed lines) and simulated (solid lines) Fourier amplitude spectra and the response spectra of acceleration are also shown

around the epicentral region. The simulation results from model 1 indicate ground motions reaching acceleration levels of $387.41 \mathrm{~cm} / \mathrm{s}^{2}$ in the epicentral region, and the peak value from model 2 is $368.60 \mathrm{~cm} / \mathrm{s}^{2}$ in the epicentral region. The simulated maximum intensity in the epicentral area was level IX on the Chinese seismic intensity scale (GB/T 17742 2008), which was similar to the observed maximum intensity.

\section{Conclusions}

In the current study, we simulated strong ground motions recorded for the Ms7.0 Jiuzhaigou earthquake based on the stochastic finite-fault method at 11 stations. We used some previous studies and empirical relationships to estimate the specific regional parameters. Based on Fourier amplitude spectra at higher frequencies, $\kappa_{0}$ for horizontal components was calculated as $0.0206 \mathrm{~s}$. Based on the slip distribution and fault dimension using the research of Zhang et al. (2017), the stochastic simulated result had no significant bias at most of the stations. Using a model with a random slip distribution, the simulated response spectra were also matched to the observed values. These results indicate that the stochastic finite-fault method is not very sensitive to the input slip distributions and fault dimensions. We used two models to simulate the ground scenario at 1116 sites. The simulated maximum intensity at the epicentral area was level IX, which was similar to the observed maximum intensity and indicates that the simulated result could be used to predict an imminent earthquake disaster.

The slip distribution plays an important role in affecting the high-frequency seismic radiation (Causse et al. 2010), and the near-field ground motion is greatly affected by the complexity of the slip distribution and rupture propagation. Perhaps the random slip distributions cause more uncertainties in the near-field groundmotion simulation. According to Beresnev et al. (1998), using the random slip models does not lead to any appreciable decrease in the accuracy of predicting the mean, nor does it increase the standard deviation compared to 

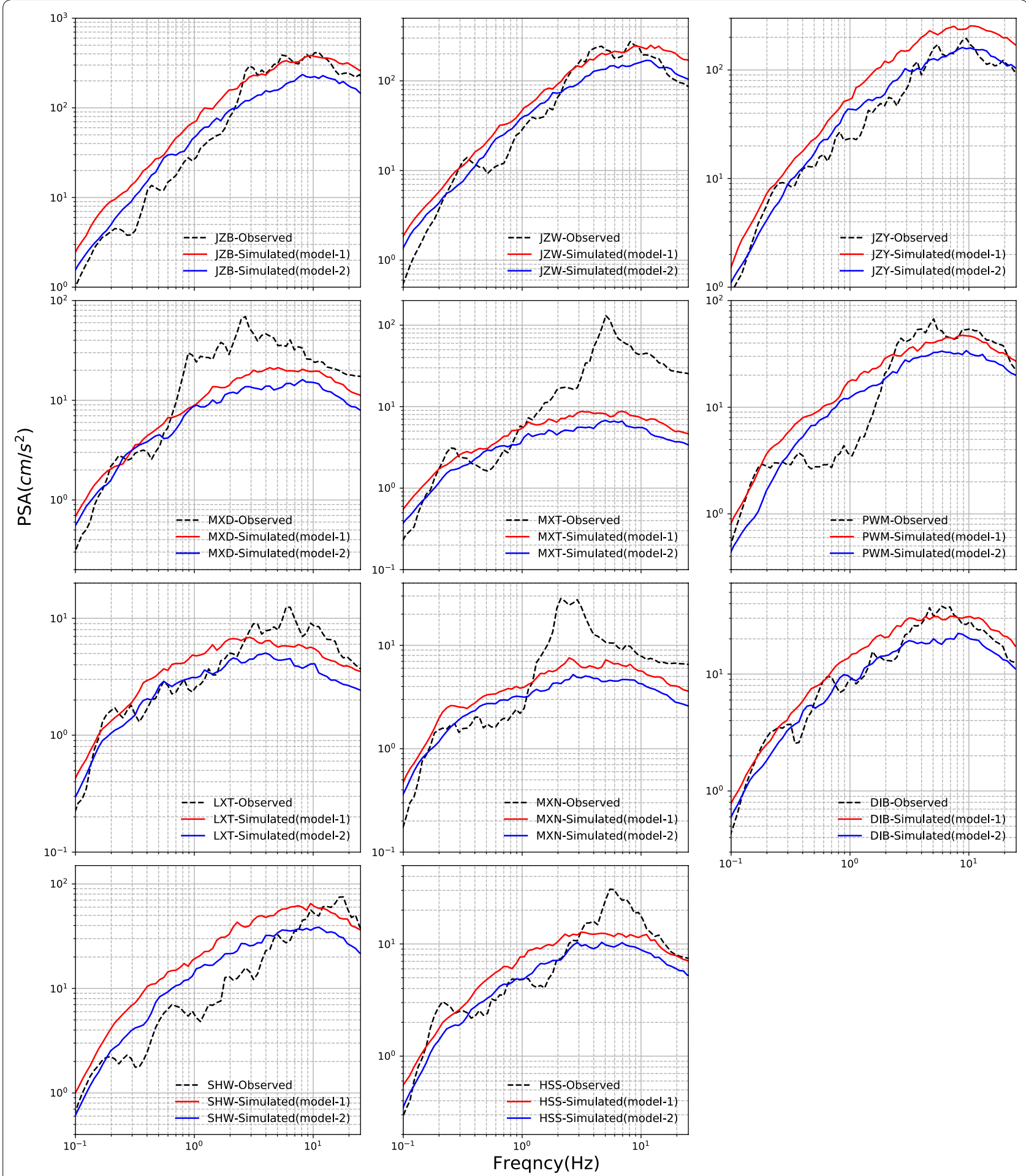

Fig. 7 Comparison of PSAs for the two models at selected stations. The observed (dashed lines) and simulated (solid lines) PSAs are shown. The red and blue lines denote simulated results from model 1 and model 2, respectively 


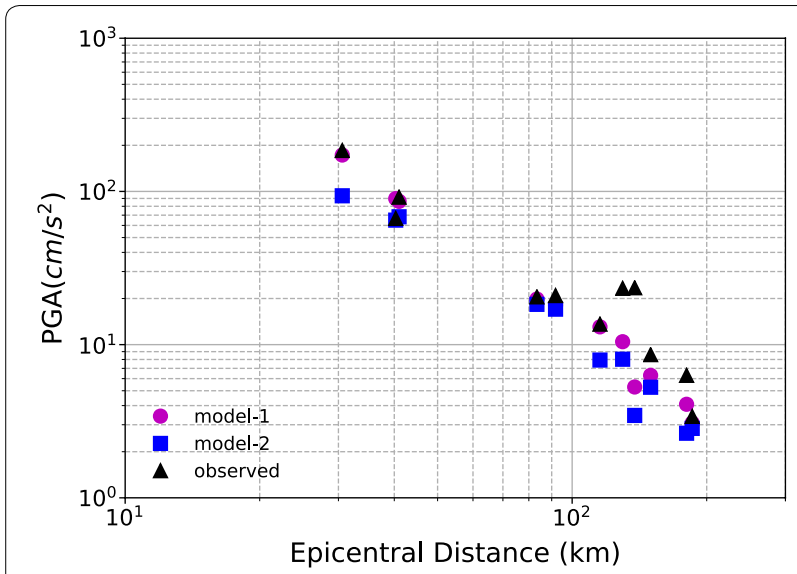

Fig. 8 Comparison of the synthesized with the recorded PGA for the two models at a selected station the actual slip distribution. Ghasemi et al. (2010) simulated the 2008 Wenchuan earthquake using two different slip models and pointed out that the quality of the simulated results decreases at longer periods without information about the slip distribution.

In the regions where real recordings are insufficient, using the stochastic finite-fault method for simulating strong ground motions is useful to understand groundmotion characteristics and distributions particularly. If we obtain enough accurate region-specific input parameters, we can reproduce realistic earthquake ground motions within the period range of engineering interest. In the field of seismic engineering, we mainly focus on the high-frequency band, especially for moderate earthquakes. For future earthquake prediction, even though we did not obtain enough information

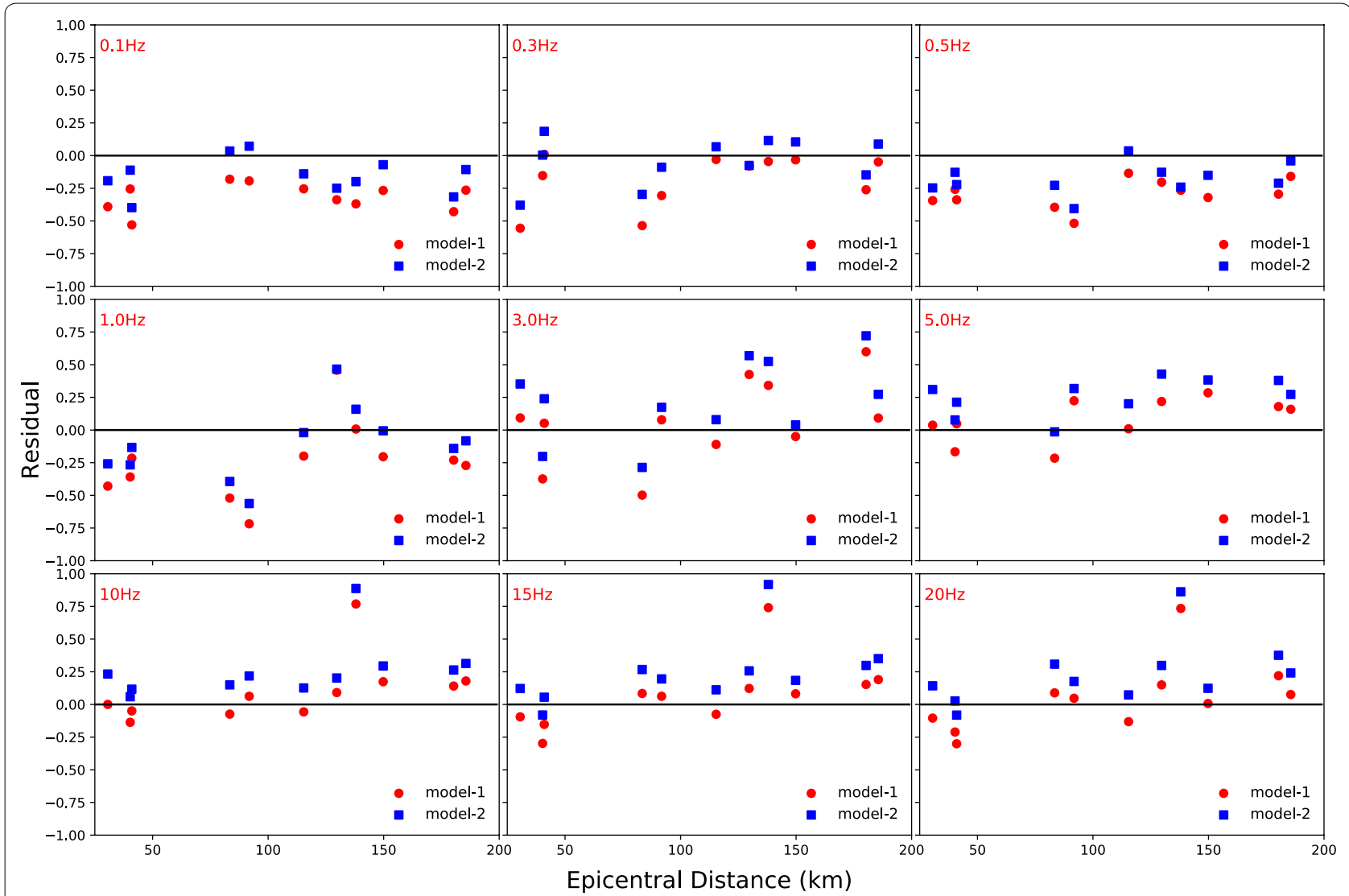

Fig. 9 Model residuals as a function of fault distance for selected spectral frequency. The red and blue cycles are the model residuals from slip model 1 and model 2, respectively 


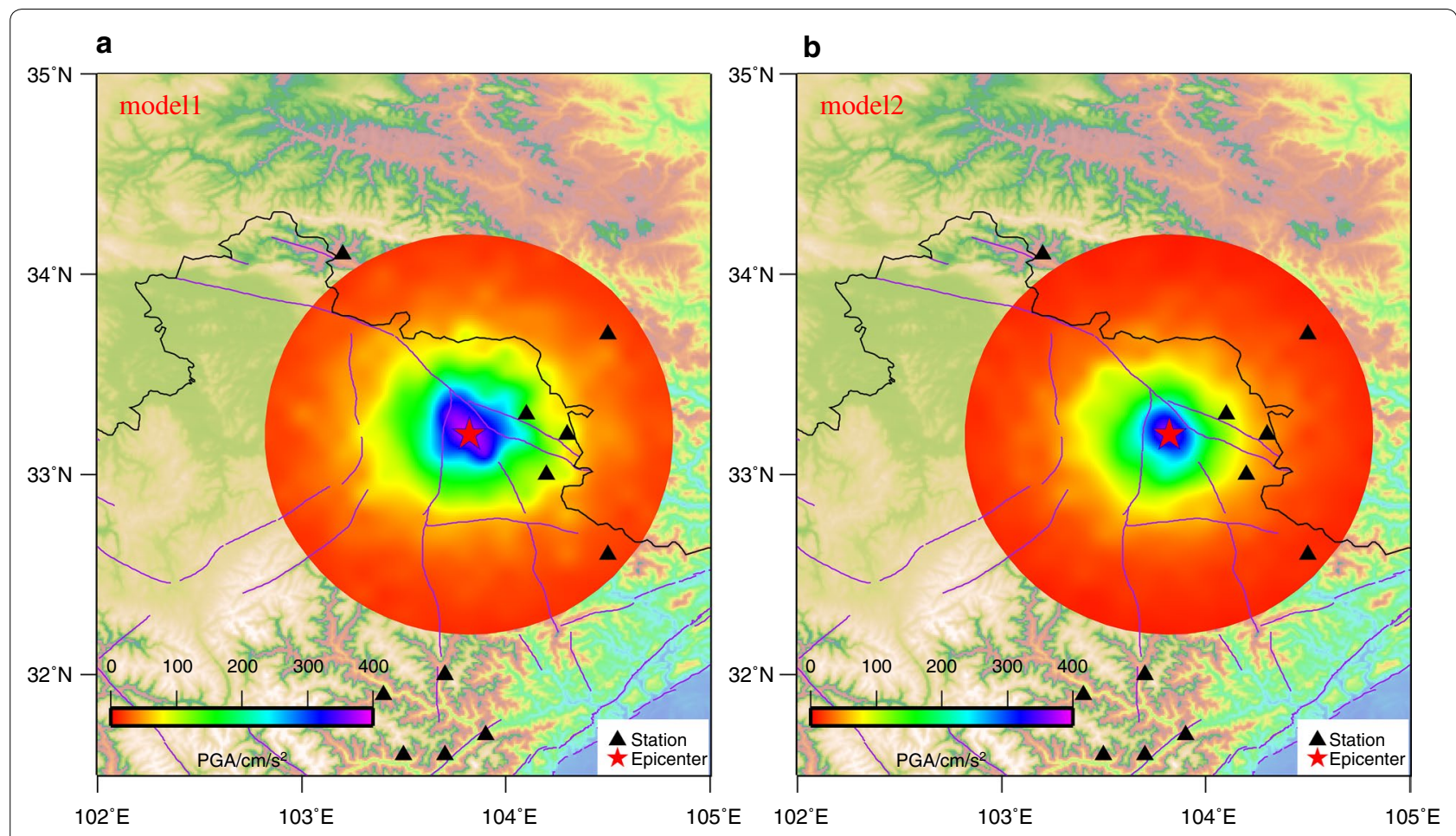

Fig. 10 a Spatial distribution of simulated PGAs from slip model 1. b Spatial distribution of simulated PGAs from slip model 2. The red solid star is the epicenter, and the black triangles represent seismic stations

about the fault plane and slip distribution, we could still estimate the intensity of ground motion if we knew the region-specific input parameters, which could be useful in studies of GMPE and ground-motion characteristics for highly seismic areas of China and in the preparation of hazard maps for these regions.

\section{Authors' contributions}

JZS analyzed the data, interpreted the results and drafted the manuscript. YXY guided the study and gave useful advice about the results. YQL took part in the design of the study. All authors read and approved the final manuscript.

\section{Author details}

${ }^{1}$ Institute of Geophysics, China Earthquake Administration, Beijing 100081, China. ${ }^{2}$ Earthquake Administration of Xinjiang Uygur Autonomous Region, Ürümqi 830011, China.

\section{Acknowledgements}

This work was supported by the National Key Research and Development Program of China (2017YFC0404901), the Special Scientific Fund Item for NonProfit Public Industry of the Ministry of Water Resources (201501034) and the National Natural Science Foundation of China (41574051). The authors also acknowledge valuable comments and suggestions provided by anonymous reviewers.

\section{Competing interests}

The authors declare that they have no competing interests.

\section{Availability of data and materials}

The ground-motion data for this study are provided by the China Strong Motion Network Center at the Institute of Engineering Mechanics, China Earthquake Administration. Ground-motion data are available through the China Earthquake Data Center (http://data.earthquake.cn/index.html).

\section{Funding}

This work is funded as Grant-in-Aid for Scientific Research by the National Key Research and Development Program of China (2017YFC0404901). This work is also supported by the Special Scientific Fund Item for Non-Profit Public Industry of the Ministry of Water Resources (201501034) and the National Natural Science Foundation of China (41574051).

\section{Publisher's Note}

Springer Nature remains neutral with regard to jurisdictional claims in published maps and institutional affiliations.

Received: 20 January 2018 Accepted: 30 July 2018

Published online: 08 August 2018

\section{References}

Anderson JG, Hough SE (1984) A model for the shape of the Fourier amplitude spectrum of acceleration at high frequencies. Bull Seismol Soc Am 74(5):1969-1993

Atkinson GM, Boore DM (1995) Ground-motion relations for eastern North America. Bull Seismol Soc Am 85:17-30

Beresnev IA, Atkinson GM, Johnson PA, Field EH (1998) Stochastic finite-fault modeling of ground motions from the 1994 Northridge, California, earthquake. II. Widespread nonlinear response at soil sites. Bull Seismol Soc Am 88(6): $1402-1410$

Boore DM (2003) Simulation of ground motion using the stochastic method. Pure appl Geophys 160(3-4):635-676. https://doi.org/10.1007/PL000 12553

Causse M, Cotton F, Mai PM (2010) Constraining the roughness degree of slip heterogeneity. J Geophys Res Solid Earth 115:B05304. https://doi. org/10.1029/2009JB006747 
China Earthquake Networks Center (2017) Sichuan Jiuzhaigou, Ms7.0, earthquake on August 8, 2017. http://data.earthquake.cn/gxdt/ info/2017/39881.html. Accessed 25 July 2018

Douglas J, Gehl P, Bonilla LF, Gélis C (2010) A k model for mainland France. Pure appl Geophys 167(11):1303-1315. https://doi.org/10.1007/s0002 4-010-0146-5

Fu L, Li XJ (2016) The characteristics of high-frequency attenuation of shear Waves in the Longmen Shan and adjacent regions. Bull Seismol Soc Am 106(5):1979-1990. https://doi.org/10.1785/0120160002

GB/T 17742 (2008) The Chinese seismic intensity scale. Standard Press of China, Beijing

Ghasemi H, Fukushima Y, Koketsu K, Miyake H, Wang Z, Anderson JG (2010) Ground-motion simulation for the 2008 Wenchuan, China, Earthquake using the stochastic finite-fault method. Bull Seismol Soc Am 100(5B):2476-2490. https://doi.org/10.1785/0120090258

Ghofrani H, Atkinson GM, Goda K, Assatourians K (2013) Stochastic finite-fault simulations of the 2011 Tohoku, Japan, earthquake. Bull Seismol Soc Am 103(2B):1307-1320. https://doi.org/10.1785/0120120228

Han L, Cheng J, An Y, Fang L, Jiang C et al (2018) Preliminary report on the 8 August 2017 Ms 7.0 Jiuzhaigou, Sichuan, China, earthquake. Seismol Res Lett. https://doi.org/10.1785/0220170158

Joyner WB, Warrick RE, Fumal TE (1981) The effect of quaternary alluvium on strong ground motion in the Coyote Lake, California, earthquake on 1979. Bull Seismol Soc Am 71(4):1333-1349

Ktenidou OJ, Abrahamson NA, Drouet S, Cotton F (2015) Understanding the physics of kappa ( $\mathrm{k}$ ): insights from a downhole array. Geophys J Int 203(1):678-691. https://doi.org/10.1093/gji/ggv315

Leonard M (2010) Earthquake fault scaling: self-consistent relating of rupture length, width, average displacement, and moment release. Bull Seismol Soc Am 100(5A):1971-1988. https://doi.org/10.1785/0120090189
Motazedian D (2006) Region-specific key seismic parameters for earthquakes in northern Iran. Bull Seismol Soc Am 96(4):1383-1395. https://doi. org/10.1785/0120050162

Motazedian D, Atkinson GM (2005) Stochastic finite-fault modelling based on a dynamic corner frequency. Bull Seismol Soc Am 95(3):995-1010. https ://doi.org/10.1785/0120030207

Roumelioti Z, Beresnev I (2003) Stochastic finite-fault modeling of ground motions from the 1999 Chi-Chi, Taiwan, earthquake: application to rock and soil sites with implications for nonlinear site response, earthquake. Bull Seismol Soc Am 93(4):1691-1702

Ugurhan B, Askan A (2010) Stochastic strong ground motion simulation of the 12 November 1999 Duzce (Turkey) earthquake using a dynamic corner frequency approach. Bull Seismol Soc Am 100(4):1498-1512. https://doi. org/10.1785/0120090358

Wang HW, Ren YF, Wen RZ (2017) Source spectra of the 8 August 2017 Jiuzhaigou Ms7.0 earthquake and the quality factor of the epicenter area. Chin J Geophys 60(10):4117-4123. https://doi.org/10.6038/cjg20171036

Yan Y, Walter JS, Bob D, Xiaojun L (2016) V $\mathrm{S}_{\$ 3}$ estimate for southwest China. Int J Geophys 1:1-11. https://doi.org/10.1155/2016/9305095

Yi GX, Long F, Liang MJ et al (2017) Focal mechanism solutions and seismogenic structure of the 8 August 2017 M7.0 Jiuzhaigou earthquake and its aftershocks, northern Sichuan. Chin J Geophys 60(10):4083-4097. https:// doi.org/10.6038/cjg20171033

Yu T, Li XJ (2012) Inversion of strong motion data for source parameters of Wenchuan aftershocks, attenuation function and average site effect. Acta Seismol Sin 34(5):621-632. https://doi.org/10.3969/j. issn.0253-3782.2012.05.004

Zhang X, Feng W, Xu L et al (2017) The source-process inversion and the intensity estimation of the 2017 Ms7.1 Jiuzhaigou earthquake. Chin J Geophys 60(10):4105-4116. https://doi.org/10.6038/cjg20171036

\section{Submit your manuscript to a SpringerOpen ${ }^{\odot}$ journal and benefit from:}

- Convenient online submission

- Rigorous peer review

- Open access: articles freely available online

- High visibility within the field

- Retaining the copyright to your article

Submit your next manuscript at springeropen.com 